\title{
Psychometric properties of the faces version of the Malay-modified child dental anxiety scale
}

\author{
Rashidah Esa ${ }^{1,2^{*}}$, Noratikah Awang Hashim³ ${ }^{3}$ Yuliana Ayob ${ }^{4}$ and Zamros Yuzadi Mohd Yusof $f^{12^{*}}$
}

\begin{abstract}
Background: To evaluate the psychometric properties of the faces version of the Modified Child Dental Anxiety Scale (MCDAS $)$ Malay version in 5-6 and 9-12 year-old children.

Methods: The MCDAS $f$ was cross culturally adapted from English into Malay. The Malay version was tested for reliability and validity in 3 studies. In the Study 1, to determine test-retest reliability of MCDAS scale, 166 preschool children aged 5-6 years were asked to rank orders five cartoons faces depicting emotions from 'very happy' to 'very sad' faces on two separate occasions 3 weeks apart. A total of 87 other 5-6 year-old children completed the Malay-MCDAS on two separate occasions 3 weeks apart to determine test-retest reliability for Study 2. In study 3, 239 schoolchildren aged 9-12 years completed the Malay-MCDAS $S_{f}$ and the Malay-Dental Subscale of the Children Fear Survey Schedule (CFSS-DS) at the same sitting to determine the criterion and construct validity.

Results: In study 1 , Kendall $W$ test showed a high degree of concordance in ranking the cartoon faces picture cards on each of the 2 occasions (time 1, W $=0.955$ and time 2, W =0.954). The Malay-MCDAS $f_{f}$ demonstrated moderate test-retest reliability (Intraclass correlation coefficient $=0.63, p<0.001$ ) and acceptable internal consistency for all the 6 items (Cronbach's alpha $=0.77$ ) and 8 items (Cronbach's alpha $=0.73$ ). The highest MCDAS scores were observed for the items 'injection in the gum' and 'tooth taken out' for both age groups. The MCDAS significantly correlated with the CFSS-DS (Pearson $r=0.67, p<0.001$ ).
\end{abstract}

Conclusions: These psychometric findings support for the inclusion of a cartoon faces rating scale to assess child dental anxiety and the Malay-MCDAS $f$ is a reliable and valid measure of dental anxiety in 5-12 year-old children.

Keywords: Dental anxiety, Children, Psychometric, Modified Child Dental Anxiety Scale faces version (MCDAS $)$

\section{Background}

Dental anxiety is a common worldwide problem affecting children as well as adults. The prevalence of dentally fearful children ranges from 3 to $55 \%$ in various populations [1-9]. Gender and age appear to be important factors linked to dental anxiety particularly common among females within the dentally anxious group in the population [10-12]. According to Hmud and Walsh [13], several factors have been shown to be related to dental anxiety including fear of pain, personal traits, traumatic dental experience during childhood and having family members or friends who are dentally anxious. The

\footnotetext{
* Correspondence: rashidah@um.edu.my; zamros@um.edu.my 'Department of Community Oral Health \& Clinical Prevention, Faculty of Dentistry, University of Malaya, 50603 Kuala Lumpur, Malaysia ${ }^{2}$ Community Oral Health Research Group, Faculty of Dentistry, University of Malaya, Kuala Lumpur, Malaysia

Full list of author information is available at the end of the article
}

assessment of children's dental anxiety is a concern as the unexpected behaviour of these children will have an impact on the management of this type of patients in the clinical setting [14]. In addition, it is important to develop appropriate measures for different cultures as studies had revealed that anxiety disorders are influenced by one's culture [14-16].

There are various methods to assess dental anxiety among children. One of the methods is by using selfreport measures. In self-report measures, dental anxiety score was obtained by asking the children directly about their anxiety with the assistance of rating scale of scoring. This method is usually in the form of questionnaire or interview. Most of these measures to assess child dental anxiety had been developed for the Western child population [17-20]. There is a need to examine alternative 
methods which may assess the dental anxiety status of young children and which provide accurate reflection of the fear they experience $[19,21,22]$.

Over the last 15 years, several studies using cartoon faces to express children's levels of dental anxiety as a Likert scale were used [23-28]. The Modified Child Dental Anxiety Scale faces version $\left(\mathrm{MCDAS}_{\mathrm{f}}\right)$ was formed by adding a cartoon faces rating scale to the original numeric form $[11,20,28]$. The psychometric properties of the $\mathrm{MCDAS}_{\mathrm{f}}$ including the reliability, criterion and construct validity had been evaluated in different populations $[11,12,15,16,22,29]$. The advantage of using this self-report measure is that it is less time consuming and easy to administer. For younger children (as young as 3 years old), the questions can be read out and the children can point to the appropriate face on the scale to indicate their anxiety level. Older children (8 years and above) were able to complete the questionnaire without assistance. Additionally, the $\mathrm{MCDAS}_{\mathrm{f}}$ is more versatile to be used for assessing dental anxiety over a wider age range for children from 5 to 12 years and those with limited cognitive functioning [11,12,16,22].

Limited studies on dental anxiety in children have been reported in Malaysia. A local study on refusal of dental treatment in the school dental service among 911 year-old schoolchildren highlighted dental anxiety as one of the reasons for refusal [30]. Another study using the Dental Fear Survey Schedule (CFSS-DS) with 10-12 year-old schoolchildren reported $15-18 \%$ of the children had high dental anxiety [7]. However, there has been no investigation of dental anxiety in preschool children and primary schoolchildren using the faces version of the MCDAS in Malaysia. It would be important to investigate if children from Malaysia could recognise the emotions expressed by cartoon faces.

The aim of this study was to evaluate the psychometric properties (reliability, criterion and construct validity) of the Malay version of the Modified Child Dental Anxiety Scale faces version $\left(\mathrm{MCDAS}_{\mathrm{f}}\right)$ in 5-6 and 9-12 year-old Malaysian schoolchildren. Findings from this study can be used to develop further the $\mathrm{MCDAS}_{\mathrm{f}}$ as a self-report measure to assess dental anxiety in young children in Malaysia.

\section{Methods}

\section{Questionnaire}

In this study, the MCDAS $\mathrm{f}$ was used as a tool to measure dental anxiety levels among 5-6 and 9-12 year-old children. This questionnaire was developed from the Modified Child Dental Anxiety Scale (MCDAS) with the addition of faces rating scale above the original numeric form to assess dental anxiety among very young and anxious children $[11,20]$. The $\mathrm{MCDAS}_{\mathrm{f}}$ consists of questions regarding several dental procedures and the child will point to the appropriate 'cartoon faces' that represents their emotions or anxiety level at that time. The scale consists of eight questions about 'going to the dentist generally', 'having teeth looked at', 'teeth being scraped and polished', 'injection in gum', 'filling', 'having tooth taken out', 'being put to sleep to have treatment' (Dental General Anaesthesia or DGA) and 'having a mixture of gas and air which will help you feel comfortable for treatment but cannot put you to sleep' (Relative Analgesia or RA). Each question has five scores ranging from relaxed or not worried to very worried in an ascending order from one to five. The minimum score is 8 and the maximum score is 40 .

The Malay-MCDAS $\mathrm{f}$ was developed from its original English version. First, the English $\mathrm{MCDAS}_{\mathrm{f}}$ was independently translated into Malay by a team of experts comprising a pedodontist, dental public health specialists and a psychologist. Then, a discussion on the translations of the Malay $\mathrm{MCDAS}_{\mathrm{f}}$ was held by the expert group. The aim was to obtain a single Malay translation which had similar conceptual meaning with the English $\mathrm{MCDAS}_{\mathrm{f}}$ using the most suitable and simple wordings in Malay. Next, the draft Malay-MCDAS $\mathrm{f}_{\mathrm{f}}$ was tested for face validation on 61, 5-6 year-old children (29 boys and 32 girls) from two kindergartens. The face validation testing was conducted in a classroom setting supervised by the researcher (RE). The children were asked to describe and rank order the five cartoon faces picture cards depicting emotions of very happy to very sad. This method was similar to an earlier study conducted by Humphris et al. [21]. It was found that all the children understood the meaning of the picture cards and were in agreement with each other on the rank order of the cartoon faces from very happy to very sad. Next, the $\mathrm{MCDAS}_{\mathrm{f}}$ items were read out by the researcher and the children were asked to answer each question using the cartoon faces picture cards as scoring options. The time taken to answer the questions was noted.

Next, a discussion on the draft Malay-MCDAS $\mathrm{f}_{\mathrm{f}}$ was carried out to assess the children's understanding on the scale's instruction, language, content and answering technique. During the discussion, it was found that almost all of the children did not understand item 7 (related to DGA) and item 8 (related to RA). These two items will be explored further in Study 2. Back translation of the 8item draft Malay-MCDAS $\mathrm{f}_{\mathrm{f}}$ was carried out by a language expert who was fluent in Malay and English language. The back translation was compared with the original $\mathrm{MCDAS}_{\mathrm{f}}$ before it was finalized. Thus, the final Malay-MCDAS consisted of 8 items together with socio-demographic information, i.e. age, gender and school.

The psychometric property of the draft Malay-MCDAS was assessed by testing it on non-random groups of children in 3 separate studies: 


\section{Study 1}

Sample

The method employed for this study is similar to an earlier study by Humphris et al. [21]. A nonprobability sample of 181 children aged between 5 to 6 years from 5 kindergartens was invited to take part in this study. Two researchers (NAH and YA) were trained in order to standardize the interview procedure. Two sets of computer line drawings of five cartoon faces were produced to replicate the emotions depicted on the $\mathrm{MCDAS}_{\mathrm{f}}$ scale. Each facial emotion was printed on a $15 \mathrm{~cm}$ by $10 \mathrm{~cm}$ index card and laminated. Every child was required to complete the task of sorting out the cards according to the scale given. The children were called individually and instructions were given by the researcher to arrange the cards accordingly from 'very happy' to 'very sad'. The cards were handed to every child at random. The individual cartoon face cards were placed onto a designated Velcro board in their perceived order from 'very happy' to 'very sad'. Once the child had completed the task, the cards were reshuffled to prepare for the next child. The researcher noted the order onto the data sheet for analysis. The same procedure was repeated for the same child after 3 weeks. On the second interview, only 166 children were present. Thus, the remaining fifteen children were excluded from the final analysis.

\section{Study 2}

Sample

Study 2 used the faces rating scale together with the MCDAS to assess children's dental anxiety level. A nonprobability sample of another 114, 5-6 year-old children from 3 preschools completed the $\mathrm{MCDAS}_{\mathrm{f}}$. The researcher read the $\mathrm{MCDAS}_{\mathrm{f}}$ items and the children chose which 'cartoon faces' that best represented their feeling. For each $\mathrm{MCDAS}_{\mathrm{f}}$ item, the response ranged from relaxed or not worried (score 1) to very worried (score 5). During the individual face to face interview, the children were briefed on the faces scale for the $\mathrm{MCDAS}_{\mathrm{f}}$. The minimum and maximum score was 8 and 40 respectively. The responses were recorded on their individual forms. The $\mathrm{MCDAS}_{\mathrm{f}}$ was then administered for the second time 3 weeks later.

\section{Study 3}

For Study 3, a non-probability sample of 250, 9-12 yearold schoolchildren were invited to complete both the Malay version of $\mathrm{MCDAS}_{\mathrm{f}}$ and the CFSS-DS at the same time. The aim of this study was to investigate the criterion and construct validity of the $\mathrm{MCDAS}_{\mathrm{f}}$ with the CFSS-DS as the 'gold standard'. In addition, the age and gender of the children were also recorded and tested for construct validity. Children from every class were randomly called by their teachers to the school hall in batches of 30 and the questionnaires were self-administered under standardised conditions. The researcher (RE) gave instructions prior to the survey. Two hundred and thirty-nine children completed both the MCDAS $\mathrm{f}$ and the CFSS-DS. Eleven participants were excluded for the final analysis due to missing values.

\section{Statistical methods}

The psychometric analysis of the draft Malay-MCDAS $\mathrm{f}$ involved the assessment of test-retest and internal reliability, as well as face, content, criterion and construct validity.

Kendall W test for the degree of concordance was used in study 1 . This test is appropriate where a set of judges is assessing the same stimuli by rank order [31]. It may also be used in the reporting of inter-test reliability [32]. Hence we calculated the degree of concordance in ranking the cartoon faces on each of the 2 occasions. It ranges from 0 (no agreement) to 1 (complete agreement) [32].

In study 2 , the test-retest reliability of Malay-MCDAS overall and individual items scores between two occasions were analyzed using t-tests and intraclass correlation coefficient. The internal reliability of items in Malay-MCDAS was assessedby using Cronbach alpha coefficient.

In Study 3, the criterion validity was assessed by using the Pearson correlation coefficient and linear regression analysis to test the association between Malay-MCDAS and the CFSS-DS. For construct validity, the ANOVA test was used to test the association between gender and age with $\mathrm{MCDAS}_{\mathrm{f}}$ and CFSS-DS scores, respectively. The mean $(95 \% \mathrm{CI})$ of each item in $\mathrm{MCDAS}_{\mathrm{f}}$ was also recorded.

In this study, the distribution of $\mathrm{MCDAS}_{\mathrm{f}}$ (Study 1, 2 and 3) and CFSS-DS scores were found to be symmetrical. Parametric statistical tests were used. All the data analyses were carried out using SPSS version 22 . The level of significance was set at $\mathrm{p}<0.05$.

\section{Ethical considerations}

Ethical approval was obtained from the Ethics Committee, Faculty of Dentistry, University of Malaya [DF OP0809/0030(L)]. Approval to conduct the study was also obtained from the Ministry of Education, Malaysia, the State Education Director, the head teachers of all participating schools and parents of the schoolchildren involved.

\section{Results}

\section{Study 1}

Test-retest reliability of the cartoon faces picture cards

Out of 181, 5-6 year-old children (mean age $=5.53$, $\mathrm{SD} \pm 0.50$ ), 166 (80 boys, 86 girls) had completed the card sort task for $\mathrm{MCDAS}_{\mathrm{f}}$ rating scale on both occasions (3 weeks interval) and were included in the statistical analysis. Thus, the response rate was $92 \%$. 
Table 1 shows the value of Kendall's W for the first and second interview. The degree of concordance in the first interview was 0.955 and the second interview was 0.954 .

\section{Study 2}

Test-retest and internal reliability of the Malay-MCDAS

Out of 114 children who were included in the study, 20 children were excluded as they were only present in the first interview and another 7 were excluded after data cleaning due to incongruent values of $\mathrm{MCDAS}_{\mathrm{f}}$ score for the first and second interview. Thus, the final response rate was $76 \%(\mathrm{n}=87 / 114)$. The mean age was 5.60 years $(\mathrm{SD} \pm 0.49)$ of which $48(55.2 \%)$ were boys. For both interviews, $48.3 \%$ and $55.2 \%$ of the children did not know about the item DGA ('being put to sleep to have treatment'). In addition, $97.7 \%$ and $100 \%$ did not know about RA ("having a mixture of "gas and air" which will help you feel comfortable for treatment but cannot put you to sleep').

Since this finding was in agreement with our face validation study, after further discussion with our expert group and interviewing three mothers, it was decided that both items were removed from the scale for this age group.

Table 2 shows the overall Malay-MCDAS $S_{f}$ score and the individual item mean scores between the two time intervals which were 3 weeks apart. The $\mathrm{MCDAS}_{\mathrm{f}}$ mean total score was significantly higher at first administration [16.61 (95\% CI: 15.68, 17.54)] than the second [14.97 (95\% CI: 14.10, 15.83)] ( $\mathrm{p}=0.001)$. Similarly, the items 'filling,' 'tooth taken out' and 'scraped and polished' scored significantly higher at first administration than the second, respectively $(\mathrm{p}<0.05)$. The other items i.e. 'dentist generally', 'teeth looked at', and 'injection in the gum' showed no significant differences between the two time intervals $(P>0.05)$. For both assessments, the highest $\mathrm{MCDAS}_{\mathrm{f}}$ scores were observed for the items 'injection in the gum' and 'tooth taken out', respectively. In terms of test-retest reliability, the intraclass correlation coefficients demonstrated good correlation with scores ranging from 0.65 to 0.77 ( $\mathrm{p}<0.001)$ for the individual items of the $\mathrm{MCDAS}_{\mathrm{f}}$ between the first and second assessments. The intraclass correlation coefficient for the mean overall $\mathrm{MCDAS}_{\mathrm{f}}$ score was 0.63 ( $\left.\mathrm{p}<0.001\right)$ between the first and second assessments. In terms of internal reliability of the Malay-MCDAS ${ }_{f}$, the corrected item-total correlation values were all positive and above

Table 1 Degree of concordance in ranking the cartoon faces on two occasions

\begin{tabular}{lllll}
\hline Visit & N & *Kendall's W & df & P-value \\
\hline First visit & 166 & 0.955 & 4 & 0.000 \\
Second visit & 166 & 0.954 & 4 & 0.000 \\
\hline
\end{tabular}

*Kendall's W coefficient of concordance.
0.3 , i.e. between 0.43 to 0.67 . The Cronbach's alpha was 0.77 and the value did not increase if any of the 6 items were deleted (Table 3).

\section{Study 3}

Criterion and construct validity of Malay-MCDAS

Out of 250, 9-12 year-old schoolchildren who were invited to complete both the Malay-MCDAS $\mathrm{f}$ and the CFSS-DS, 11 participants were excluded due to missing values. Two hundred and thirty-nine children completed both the $\mathrm{MCDAS}_{\mathrm{f}}$ and the CFSS-DS. Another 9 participants did not know or did not respond to the 2 items on DGA and RA. Thus they were excluded from the final analysis giving a final response rate of $92 \%(n=230 / 250)$ and the 8-item Malay-MCDAS $\mathrm{f}_{\mathrm{f}}$ was used for this age group. Majority were Malays (72.2\%), followed by Indians $(23 \%)$, Chinese (3\%) and others $(1.7 \%)$. There were slightly more boys $(\mathrm{n}=121,52.6 \%)$ and their mean age was 9.87 years $(\mathrm{SD} \pm 0.77)$.

The mean overall score for the $\mathrm{MCDAS}_{\mathrm{f}}$ was 21.77 (95\% CI: 21.01, 22.53), with a range of scores from 8 to 40. The mean overall score for the CFSS-DS was 37.57 (95\% CI: 36.09, 39.05), with a range of scores from 15 to 71. In this age group, the corrected item-total correlation values were all positive and above 0.3 , i.e. between 0.31 to 0.54 for $\mathrm{MCDAS}_{\mathrm{f}}$ (Table 4). Similarly, the corrected item-total correlation values for CFSS-DS were also all positive and above 0.3 , i.e. between 0.31 to 0.65 . The Cronbach's alpha coefficients of $\mathrm{MCDAS}_{\mathrm{f}}$ and CFSS-DS were 0.73 and 0.87 , respectively.

For criterion validity testing, the mean overall scores for the $\mathrm{MCDAS}_{\mathrm{f}}$ and the CFSS-DS were significantly correlated (Pearson $\mathrm{r}=0.67, \mathrm{p}<0.001$ ), where $45 \%$ of the variance in CFSS-DS was explained by $\mathrm{MCDAS}_{\mathrm{f}}$ (Table 5).

For construct validity, the variance of dental anxiety as assessed by MCDAS $_{\mathrm{f}}$ and CFSS-DS was analysed across gender and age (Tables 6 and 7). Girls had significantly higher mean scores for dental anxiety compared to boys for both the MCDAS and CFSS-DS $(\mathrm{p}<0.001)$. There were no significant differences in mean scores between the three age groups for both the $\mathrm{MCDAS}_{\mathrm{f}}$ and CFSSDS ( $\mathrm{p}>0.05)$.

\section{Discussion}

In this study, the development of the Malay-MCDAS followed a recommended method [33] and was closely related to other similar studies on the index validation $[11,23,24,29]$. The forward and back translations of the 8-item $\mathrm{MCDAS}_{\mathrm{f}}$ were done by local experts in dental public health, pediatric dentistry, child psychologist and Malay and English languages. The experts unanimously agreed that the Malay-MCDAS $\mathrm{f}$ and its original English version had similar subject content and meanings of its items. The final back translation of Malay-MCDAS $\mathrm{f}_{\mathrm{f}}$ into 
Table 2 Overall and Individual item mean scores of Malay-MCDAS ${ }_{f}$ between two time intervals for 5-6 year-old children

\begin{tabular}{|c|c|c|c|c|}
\hline \multirow[t]{2}{*}{$\mathrm{N}=87$} & \multirow{2}{*}{$\begin{array}{l}\text { First visit } \\
\text { Mean }(95 \% \mathrm{Cl})\end{array}$} & \multirow{2}{*}{$\begin{array}{l}\text { Second visit } \\
\text { Mean }(95 \% \mathrm{Cl})\end{array}$} & \multirow[t]{2}{*}{$\mathrm{t}$ value } & \multirow[t]{2}{*}{ P-value } \\
\hline & & & & \\
\hline Mean $\mathrm{MCDAS}_{\mathrm{f}}$ Score & $16.61(15.68,17.54)$ & $14.97(14.10,15.83)$ & 3.50 & 0.001 \\
\hline Dentist generally & $1.76(1.54,1.98)$ & $1.57(1.39,1.76)$ & -1.43 & 0.155 \\
\hline Teeth looked at & $1.91(1.71,2.11)$ & $1.91(1.72,2.09)$ & 0.00 & 1.000 \\
\hline Scraped and polished & $2.28(2.04,2.51)$ & $1.86(1.65,2.07)$ & -2.60 & 0.011 \\
\hline Injection in the gum & $3.66(3.43,3.88)$ & $3.77(3.49,4.05)$ & 0.88 & 0.380 \\
\hline Filling & $2.95(2.70,3.21)$ & $2.18(1.93,2.44)$ & -4.74 & 0.001 \\
\hline Tooth taken out & $4.06(3.84,4.28)$ & $3.67(3.38,3.95)$ & -2.79 & 0.006 \\
\hline
\end{tabular}

Paired $t$ Test.

Two items, 'dental general anaesthesia' and 'relative analgesia' items were omitted for this age group.

its English version contained many similar words with the original $\operatorname{MCDAS}_{\mathrm{f}}$. The slight differences in the wordings between the two were due to cultural variations and children's preferences in the choice of words during pretest of the Malay MCDAS $\mathrm{f}_{\mathrm{f}}$ In general, the study findings suggest that the Malay-MCDAS $\mathrm{S}_{\mathrm{f}}$ has high potential to measure dental anxiety among Malaysian preschool and schoolchildren. Its linguistic validation, i.e. face and content validity and psychometric validation, i.e. internal reliability, test-retest reliability, criterion and construct validity had been tested and verified by experts and statistical analyses.

In Malaysia, children start primary school at the age of 7 until 12 years, and at 5 to 6 years they are in preschool. The oral healthcare programme for preschool children launched in 1984, covers 5-6 year-old children attending kindergartens and pre-schools. This programme focuses on a friendly, non-invasive approach whereby dental nurses introduced dentistry to children via promotional and preventive initiatives and visit the children twice a year. These include tooth brushing sessions, puppet shows, role-play and other fun activities. The Atraumatic

Table 3 Reliability analysis: corrected item-total correlation of the 6 items of the Malay-MCDAS ${ }_{\mathrm{f}}$ and Cronbach's Alpha coefficients for 5-6 year-old children

\begin{tabular}{lll}
\hline & $\begin{array}{l}\text { Corrected item-total } \\
\text { correlation }\end{array}$ & $\begin{array}{l}\text { Cronbach's alpha } \\
\text { if item deleted }\end{array}$ \\
\hline Dentist generally & .429 & .76 \\
Teeth looked at & .483 & .75 \\
Scraped and polished & .526 & .74 \\
Injection in the gum & .583 & .72 \\
Filling & .446 & .76 \\
Tooth taken out & .671 & .70 \\
Alpha value & & .77 \\
Standardised items alpha & & .78 \\
\hline
\end{tabular}

Two items, 'dental general anaesthesia' and 'relative analgesia' items were omitted for this age group.
Restorative Technique (ART) is adopted to provide necessary restorative care for the children [34]. The three studies were conducted simultaneously to evaluate the overall psychometric properties of the Malay-MCDAS $\mathrm{f}_{\mathrm{f}}$ to validate its use by both preschool and primary schoolchildren in Malaysia.

At the face validation stage, it was found that the majority of the 5-6 year-old children were not able to distinguish between DGA and RA with the majority of children stated they were unafraid. When the children were asked about these procedures it became apparent that they did not know about DGA or RA [22]. This finding was not surprising as general anesthesia is used selectively for dental extractions in Malaysia [35] and RA is rarely used for paediatric dental patients in Malaysia. Furthermore, evidence had shown that the most effective drug or method of sedation used for anxious children are still debatable [36]. Additionally, Study 2 also showed that majority did not know about DGA and almost all were

Table 4 Reliability analysis: corrected item-total correlation of the 8 items of the Malay-MCDAS ${ }_{f}$ and Cronbach's Alpha coefficients for 9-12 year-old children

\begin{tabular}{llll}
\hline & Mean (SD) & $\begin{array}{l}\text { Corrected } \\
\text { item-total } \\
\text { correlation }\end{array}$ & $\begin{array}{l}\text { Cronbach's } \\
\text { alpha if item } \\
\text { deleted }\end{array}$ \\
\hline Dentist generally & $1.96(0.98)$ & .310 & .72 \\
Teeth looked at & $2.23(1.15)$ & .539 & .68 \\
Scraped and polished & $2.60(1.28)$ & .473 & .69 \\
Injection in the gum & $3.90(1.21)$ & .435 & .70 \\
Filling & $2.82(1.36)$ & .499 & .68 \\
Tooth taken out & $3.63(1.34)$ & .431 & .70 \\
DGA* & $2.15(1.26)$ & .333 & .72 \\
RA* & $2.48(1.40)$ & .353 & .72 \\
Alpha value & & & .73 \\
Standardised items alpha & & & .73 \\
\hline
\end{tabular}

*DGA - Dental General Anaesthesia.

*RA - Relative Analgesia. 
Table 5 Summary statistics of linear regression analysis for MCDAS $_{\mathrm{f}}$ and CFSS-DS

\begin{tabular}{lllllll}
\hline Dependent & $\mathbf{R}$ & $\mathbf{R}$ square & Std. error & $\mathbf{d f}$ & $\mathbf{F}$ & Sig. \\
\hline CFSS-DS & 0.672 & 0.452 & 4.366 & 1 & 187.698 & 0.000 \\
\hline
\end{tabular}

Predictors: (Constant), $\mathrm{MCDAS}_{\mathrm{f}}$ score.

Dependent variable: CFSS-DS score.

not aware of RA. Therefore it was decided to omit these two items from the Malay-MCDAS for the 5-6 year-old children due to their lack of experience and understanding of both types of treatments. However, these two items were used for the 9-12 year-old children. Christophorou et al. [12] and Javadinejad et al. [16] had also employed the 8-item version of the MCDAS for 8-12 year-old primary schoolchildren.

The results from Study 1 indicated that preschool children in Malaysia possessed the right levels of cognitive and affective abilities to discriminate between happy and sad faces on the cartoon faces rating scale. The degree of concordance was high and almost similar for the first as well as the second administration of the play board of cartoon faces. The Kendall's W coefficient of concordance value showed nearly perfect ranking from very happy, happy, neutral, sad, and very sad emotions. This finding was in resemblance with findings from other similar studies which reported consistent rank ordering employing cartoon faces (very happy-happy-sad-very sad) or using the Facial Image Scale in the assessment of dental anxiety in young children [23-25].

In Study 2, in terms of its reliability test, the corrected item-total correlation values for all the 6 items were well above 0.2 , indicating all the Malay-MCDAS $\mathrm{f}_{\mathrm{f}}$ items correlated well with the sum score. This indicated the 6 items were stable to form an index and had high internal

Table 6 Association between MCDAS $_{\mathrm{f}}$ scores with demographic characteristics of the school children

\begin{tabular}{|c|c|c|c|c|}
\hline $\begin{array}{l}\text { Demographic } \\
\text { variable }\end{array}$ & N (\%) & $\begin{array}{l}\text { Mean } \\
\text { MCDAS }_{\mathrm{f}}\end{array}$ & $95 \% \mathrm{Cl}$ & p-value \\
\hline \multicolumn{5}{|l|}{ Gender } \\
\hline Boys & $121(52.6)$ & 20.45 & $\begin{array}{l}19.42 \\
21.48\end{array}$ & 0.000 \\
\hline Girls & 109 (47.4) & 23.23 & $\begin{array}{l}22.14 \\
24.32\end{array}$ & \\
\hline \multicolumn{5}{|l|}{ Age (years) } \\
\hline 9 & 79 (34.3) & 21.14 & $\begin{array}{l}19.78 \\
22.50\end{array}$ & \\
\hline 10 & 107 (46.5) & 21.93 & $\begin{array}{l}20.84 \\
23.02\end{array}$ & 0.436 \\
\hline *11-12 & $44(19.2)$ & 22.50 & $\begin{array}{l}20.68 \\
24.32\end{array}$ & \\
\hline $\begin{array}{l}\text { Overall Mean MCDAS } \\
\text { score }\end{array}$ & 230 & 21.77 & $\begin{array}{l}21.01 \\
22.53\end{array}$ & \\
\hline
\end{tabular}

*5, 12-year-old children were included in the 11-year-old group as they were in the same grade.
Table 7 Association between CFSS-DS scores with demographic characteristics of the school children

\begin{tabular}{lllll}
\hline $\begin{array}{l}\text { Demographic } \\
\text { variable }\end{array}$ & N (\%) & $\begin{array}{l}\text { Mean } \\
\text { CFSS-DS }\end{array}$ & 95\% Cl & p-value \\
\hline Gender & & & & \\
Boys & $121(52.6)$ & 35.26 & 33.34, & 0.001 \\
& & & 37.18 & \\
Girls & $109(47.4)$ & 40.14 & 37.92, & \\
& & & 42.35 &
\end{tabular}

Age (years)

$\begin{array}{llll}9 & 79(34.3) & 37.80 & 35.27\end{array}$

40.32

$\begin{array}{lllll}10 & 107(46.5) & 37.97 & 35.73, & 0.666\end{array}$

*11-12 $44(19.2) \quad 36.18 \quad 32.84$,

39.53

$\begin{array}{lll}230 & 37.57 & 36.09 \\ \text { score } & 39.05\end{array}$

*5, 12-year-old children were included in the 11-year-old group as they were in the same grade.

reliability [32]. Also, the Cronbach's alpha value was 0.77 indicating the 6 item Malay-MCDAS $\mathrm{f}_{\mathrm{f}}$ was reliable to measure dental anxiety among 5-6 year-old preschool children in Malaysian setting. If any of the items were removed, the value of Cronbach's alpha did not increase. This indicated no item should be removed to further improve the scale reliability. As for the test-retest reliability of the Malay-MCDAS $\mathrm{M}_{\mathrm{f}}$, the relatively high intraclass correlation coefficient values of individual items and mean scores when the scale was fielded at two different times indicated the Malay-MCDAS $\mathrm{f}_{\mathrm{f}}$ was reliable in producing consistent outcomes.

The differences in the mean scores for the six items of the Malay-MCDAS $\mathrm{f}_{\mathrm{f}}$ showed that children were able to discriminate between more invasive treatment procedures such as 'tooth taken out, 'injection', 'filling' and 'scraped and polished' which had higher mean scores compared to less invasive treatment such as 'having teeth looked at' or 'dentist generally'. The slightly lower mean scores obtained for the second test could be explained by a practice effect since the children were already familiar with the items. However, for injection in the gums' the score for the second test was slightly higher than the first test but it was not statistically significant. Howard and Freeman [11] similarly cited that the item 'injection in the gums' as the greatest level of dental anxiety. Interestingly, the 8 item Malay-MCDAS for the 9-12 year-old children also highlighted similar anxiety provoking stimulus. The item scores for DGA and RA were quite similar to the non-invasive items of the $\mathrm{MCDAS}_{\mathrm{f}}$. possibly due to non-exposure to these procedures.

Howard and Freeman [11] showed that a two-factor structure namely 'examination' and 'treatment' existed 
for the $\mathrm{MCDAS}_{\mathrm{f}}$ in their sample. However, Zhang et al. [29] confirmed that the Chinese version of the MCDAS scale consisted of a single unidimensional construct (written in Chinese). Similarly, Christophorou et al. [12] also confirmed a clear unidimensional structure for the Greek version of MCDAS. Hence it would be preferable to test the Malay-MCDAS $\mathrm{S}_{\mathrm{f}}$ on a larger sample size so that a confirmatory factor analytic approach and structural equation modelling could be applied. This would help to confirm if a two-factor structure for the Malay version of the $\mathrm{MCDAS}_{\mathrm{f}}$ existed in this child population.

In Study 3, the Malay-MCDAS $\mathrm{f}_{\mathrm{f}}$ was tested against the Malay-CFSS-DS which is the 'gold standard' among 9-12 year-old children to measure dental anxiety $[11,22,37,38]$. Although the internal consistency of $\mathrm{MCDAS}_{\mathrm{f}}$ was lower being 0.73 as compared to 0.86 for CFSS-DS, it was still within the acceptable range for Cronbach's alpha [39]. A possible explanation for this difference could be due to the fact that the $\mathrm{MCDAS}_{\mathrm{f}}$ only contained 8 items compared to 15 items of CFSS-DS used in this study. Nevertheless, there was a significant correlation between the mean overall scores for the $\mathrm{MCDAS}_{\mathrm{f}}$ and the CFSS-DS where $45 \%$ of the variance in CFSS-DS was explained by $\mathrm{MCDAS}_{\mathrm{f}}$. Both these findings indicated that $\mathrm{MCDAS}_{\mathrm{f}}$ has good internal consistency and good criterion validity in relation to the CFSS-DS.

In terms of the construct validity, the variance of dental anxiety as assessed by $\mathrm{MCDAS}_{\mathrm{f}}$ and CFSS-DS demonstrated similar findings that girls had significantly higher mean scores for dental anxiety compared to boys. With regard to age groups, both the MCDAS $\mathrm{f}$ and CFSS-DS showed no significant difference in mean scores between the three age groups. These findings indicated that the Malay-MCDAS $_{\mathrm{f}}$ had similar construct validity with the Malay-CFSS-DS in the Malaysian setting. Thus, it could be said that the Malay-MCDAS $\mathrm{f}_{\mathrm{f}}$ was equally valid to assess dental anxiety among school children in Malaysia similar to the 'gold standard,' CFSS-DS (Malay version).

One of the limitations of this study was the sample. All three studies used urban children with varying socioeconomic background and adequate gender distribution. It is recommended that future study to further validate the Malay-MCDAS $\mathrm{f}_{\mathrm{f}}$ is conducted on a larger sample of rural children and other ethnic groups. Further longitudinal study on the same population is also recommended to assess dental anxiety over time.

Previous studies had established that children and adolescents with high caries experience exhibited high dental anxiety $[11,40,41]$. Another limitation of this study is that $\mathrm{MCDAS}_{\mathrm{f}}$ was not tested against any clinical measure of oral health or in a clinical situation between anxious and non-anxious children. Further studies should look into these areas and establish suitable cut off level for dental anxiety in this population. Despite these limitations, the 6-item and 8-item Malay-MCDAS $\mathrm{f}_{\mathrm{f}}$ has been shown to be valid and reliable to be used as a screening tool across a wider age range in children survey as well as prior to dental procedures in the clinic.

\section{Conclusions}

The psychometric properties of the Malay-MCDAS $\mathrm{M}_{\mathrm{f}}$ provided empirical evidence to support for the inclusion of a cartoon faces rating scheme in the scale to assess child dental anxiety in children. The 6-item Malay-MCDAS $\mathrm{S}_{\mathrm{f}}$ is recommended for assessing dental anxiety for 5-6 yearold and younger children whereas the 8-item Malay$\mathrm{MCDAS}_{\mathrm{f}}$ can be used for older children. Both versions had been verified to be valid and reliable to measure dental anxiety in 5-12 year-old children.

\section{Abbreviations}

ANOVA: Analysis of variance; ART: Atraumatic restorative technique; DGA: Dental general anaesthesia; CFSS-DS: Dental subscale of the children fear survey schedule; MCDAS: Modified child dental anxiety scale; MCDAS: Modified child dental anxiety scale faces version; RA: Relative analgesia.

\section{Competing interests}

The authors declare that they have no competing interests.

\section{Authors' contributions}

RE and ZYY were the principal investigators of the study. NAH and YA were involved in Study 1 and 2. RE and ZYY have revised the manuscript. All authors read and approved the final manuscript.

\section{Acknowledgements}

The assistance of the head teachers of all participating schools, parents and the children's participation is gratefully acknowledged. The authors would like to thank Professor Gerry Humphris and Professor Ruth Freeman for their assistance in developing this investigation. We also would like to express our special thanks to University Malaya for funding this study (FS 155/2008B).

\section{Author details}

${ }^{1}$ Department of Community Oral Health \& Clinical Prevention, Faculty of Dentistry, University of Malaya, 50603 Kuala Lumpur, Malaysia. ${ }^{2}$ Community Oral Health Research Group, Faculty of Dentistry, University of Malaya, Kuala Lumpur, Malaysia. ${ }^{3}$ Oral Health Division, Ministry of Health, Pitas, Sabah,

Malaysia. ${ }^{4}$ Oral Health Division, Ministry of Health, Kuching, Sarawak, Malaysia.

Received: 3 October 2014 Accepted: 19 February 2015

Published online: 10 March 2015

\section{References}

1. Klingberg G, Berggren U, Noren JG. Dental fear in an urban Swedish child population: prevalence and concomitant factors. Community Dent Health. 1994;11(4):208-14.

2. Desiate A, Fanelli M, Milano V. "Odontogenic" anxiety. A study of a population of 1500 students from the public schools in the Bari area. Minerva Stomatol. 1997:46(4):165-73.

3. Chellappah NK, Vignehsa H, Milgrom P, Lam LG. Prevalence of dental anxiety and fear in children in Singapore. Community Dent Oral Epidemiol. 1990;18(5):269-71.

4. Rantavuori K, Zerman N, Ferro R, Lahti S. Relationship between children's first dental visit and their dental anxiety in the Veneto Region of Italy. Acta Odontol Scand. 2002;60(5):297-300.

5. Nakai $Y$, Hirakawa T, Milgrom P, Coolidge T, Heima M, Mori $Y$, et al. The children's fear survey schedule-dental subscale in Japan. Community Dent Oral Epidemiol. 2005:33(3):196-204.

6. Milsom KM, Tickle M, Humphris GM, Blinkhorn AS. The relationship between anxiety and dental treatment experience in 5-year-old children. Br Dent J. 2003;194(9):503-6. 
7. Shahardin RZR. Dental anxiety among 10-12 year-old schoolchildren in Malaysia. Kuala Lumpur, Malaysia: M Clint Dent Report, University of Malaya; 2003.

8. Lee CY, Chang YY, Huang ST. Prevalence of dental anxiety among 5- to 8-year-old Taiwanese children. J Public Health Dent. 2007;67(1):36-41.

9. Rantavuori K, Lahti S, Hausen H, Seppa L, Karkkainen S. Dental fear and oral health and family characteristics of Finnish children. Acta Odontol Scand. 2004;62(4):207-13.

10. Armfield JM, Spencer AJ, Stewart JF. Dental fear in Australia: who's afraid of the dentist? Aust Dent J. 2006;51(1):78-85.

11. Howard KE, Freeman R. Reliability and validity of a faces version of the modified child dental anxiety scale. Int J Paediatr Dent. 2007;17(4):281-8.

12. Christophorou S, Lee GTR, Humphris GM. The reliability and validity of the modified child dental anxiety scale: a study of Greek Cypriot school children. Eur J Paediatr Dent. 2000;1(2):75-81.

13. Hmud R, Walsh L. Dental anxiety: causes, complications and management approaches. J Minim Interv Dent. 2009;2(1):67-78.

14. Lee CY, Chang YY, Huang ST. The clinically related predictors of dental fear in Taiwanese children. Int J Paediatr Dent. 2008;18(6):415-22.

15. Coolidge T, Hillstead MB, Farjo N, Weinstein P, Coldwell SE. Additional psychometric data for the Spanish modified dental anxiety scale, and psychometric data for a Spanish version of the revised dental beliefs survey. BMC oral health. 2010;10:12.

16. Javadinejad S, Farajzadegan Z, Madahain M. Iranian version of a face version of the modified child dental anxiety scale: transcultural adaptation and reliability analysis. J Res Med Sci. 2011;16(7):872-7.

17. Venham LL, Gaulin-Kremer E. A self-report measure of situational anxiety for young children. Pediatr Dent. 1979;1(2):91-6.

18. Cuthbert MI, Melamed BG. A screening device: children at risk for dental fears and management problems. ASDC J Dent Child. 1982;49(6):432-6.

19. Alvesalo I, Murtomaa H, Milgrom P, Honkanen A, Karjalainen M, Tay KM. The dental fear survey schedule: a study with Finnish children. Int J Paediatr Dent. 1993;3(4):193-8.

20. Wong HM, Humphris GM, Lee GT. Preliminary validation and reliability of the modified child dental anxiety scale. Psychol Rep. 1998;83(3 Pt 2):1179-86.

21. de Jongh A, Muris P, ter Horst G, Duyx MP. Acquisition and maintenance of dental anxiety: the role of conditioning experiences and cognitive factors. Behav Res Ther. 1995;33(2):205-10.

22. Porritt J, Buchanan H, Hall M, Gilchrist F, Marshman Z. Assessing children's dental anxiety: a systematic review of current measures. Community Dent Oral Epidemiol. 2013;41(2):130-42.

23. Humphris GM, Milsom K, Tickle M, Holbrook H, Blinkhorn A. A new dental anxiety scale for 5-year-old children (DA5): description and concurrent validity. Health Educ J. 2002;61:5-19.

24. Buchanan $\mathrm{H}$, Niven $\mathrm{N}$. Validation of a facial image scale to assess child dental anxiety. Int J Paediatr Dent. 2002;12(1):47-52.

25. Buchanan $\mathrm{H}$, Niven $\mathrm{N}$. Further evidence for the validity of the facial image scale. Int J Paediatr Dent. 2003;13(5):368-9.

26. Buchanan $\mathrm{H}$. Development of a computerised dental anxiety scale for children: validation and reliability. Br Dent J. 2005;199(6):359-62. discussion 351; quiz 372

27. Buchanan $\mathrm{H}$. Assessing dental anxiety in children: the revised smiley faces program. Child Care Health Dev. 2010;36(4):534-8.

28. Howard KE. Measuring and managing child dental anxiety. Phd thesis: Queen's University Belfast; 2006.

29. Zhang HM, Xia B, Wang JH, Xie P, Huang Q, Ge LH. Chinese version of a face version of the modified child dental anxiety scale: transcultural adaptation and evaluation. Chinese J Stomatol. 2013;48(7):403-8.

30. Dayang Mariam AR, Ahmad A, Sujak SL, Noralaini I, Nooraini O, Fouziah G, et al. Refusal of dental treatment in the school dental service among primary schoolchildren. Int Dent J. 2001;51(5):360.

31. Siegel S, Castellan Jr NJ. Nonparametric Statistics for the Behavioural Sciences. Singapore: McGraw-Hill Book Co.; 1988.

32. Field A. Discovering Statistics Using SPSS. 2nd ed. London: Sage Publications Ltd.; 2005.

33. Acquadro C, Conway K, Giroudet C, Mear I. Linguistic validation manual for patient-reported outcomes (PRO) instruments. Lyon: Mapi Research Institute; 2004.

34. Oral Health Division Ministry of Health Malaysia. Oral Healthcare in Malaysia. Putrajaya: Oral Health Division Ministry of Health Malaysia; 2008.
35. Karim ZA, Musa N, Noor SN. Utilization of dental general anaesthesia for children. Malays J Med Sci. 2008;15(3):31-9.

36. Matharu LL, Ashley PF. What is the evidence for paediatric dental sedation? J Dent. 2007:35(1):2-20.

37. Aartman $\mathrm{H}$, van Everdingen T, Hoogstraten J, Schuurs AH. Self-report measurements of dental anxiety and fear in children: a critical assessment. ASDC J Dent Child. 1998;65(4):252-8. 229-230.

38. Lopes D, Arnrup K, Robertson A, Lundgren J. Validating the dental subscale of the children's fear survey schedule using Rasch analysis. Eur J Oral Sci. 2013;121(3 Pt 2):277-82.

39. Streiner DL, Norman GR. Health Measurement Scales. A Practical Guide to their Development and Use. 2nd ed. Oxford: Oxford Medical Publications; 1995.

40. Bedi R, Sutcliffe P, Donnan P, Barrett N, McConnachie J. Dental caries experience and prevalence of children afraid of dental treatment. Community Dent Oral Epidemiol. 1992;20(6):368-71.

41. Esa $R$, Ong AL, Humphris $G$, Freeman $R$. The relationship of dental caries and dental fear in Malaysian adolescents: a latent variable approach. BMC Oral Health. 2014;14:19.

\section{Submit your next manuscript to BioMed Central and take full advantage of:}

- Convenient online submission

- Thorough peer review

- No space constraints or color figure charges

- Immediate publication on acceptance

- Inclusion in PubMed, CAS, Scopus and Google Scholar

- Research which is freely available for redistribution 